\title{
One-year outcomes of infants born with congenital diaphragmatic hernia: a national population cohort study
}

\author{
Long $\mathrm{AM}^{1,2}$, Bunch $\mathrm{KJ}^{1}$, Knight $\mathrm{M}^{1}$, Kurinczuk $\mathrm{JJ}^{1}$, Losty PD ${ }^{3,4}$ - On behalf of BAPS-CASS*
}

\section{Author Affiliations}

1. National Perinatal Epidemiology Unit, University of Oxford

2. Cambridge University Hospitals NHS Foundation Trust, Cambridge

3. Alder Hey Children's Hospital, Liverpool

4. Institute of Child Health, University of Liverpool

\section{Corresponding Author}

Professor Paul Losty MD FRCSI FRCS(Ed) FRCS(Eng) FRCS(Paed) FEBPS

Professor of Paediatric Surgery

Department of Women and Children's Health

Institute of Translational Medicine

University of Liverpool

Alder Hey Children's Hospital NHS Foundation Trust

East Prescot Rd

Liverpool L14 5AB, UK

Tel: 00-44-151 2284811

Email : paul.Losty@liverpool.ac.uk

\section{Source of Funding}

Action Medical Research

\section{Category of submission}

Original article

*Collaborators: Marven S, Draper E, Johnson P, Brocklehurst P, Howe D, Rankin J, Aslam A, Jawaid W, Wilkinson D, Robb A, Lander A, Burki T, Coates L, Cusick E, Fishman J, Madden N, Adikibi B, Mackinlay G, Sabharwal A, Larcombe C, Curry J, Besarovic S, Ashour K, Johnson P, Carnaghan H, Davenport M, Sugarman I, Nour S, Tsang T, Paul A, Davies B, Mclaughlin D, Puri P, Abel R, Driver C, Mahomed A, Ervine E, Mccallion W, Phelps S, Craigie R, Morabito A, La Hunt M, Hosie G, Lloyd K, Taylor R, Drewett M, Okoye B, Richards C, King J, Nellihala LP, de La Hunt M, Huddart S. 


\section{Abstract}

Objective To report outcomes to one-year, in infants born with congenital diaphragmatic hernia(CDH), explore factors associated with infant mortality and examine the relationship between surgical techniques and post-operative morbidity.

Design Prospective national population cohort study

Setting Paediatric surgical centres in the UK and Ireland

Method Data were collected to one-year for infants with CDH live-born between 01/04/2009 to 30/09/2010. Factors associated with infant mortality are explored using logistic regression. Postoperative morbidity following patch vs primary closure, minimally invasive vs open surgery and biological vs synthetic patch material is described. Data are presented as $n(\%)$ and median(IQR).

Results Overall known survival to one-year was 75\%, 95\%Cl 68-81\% (138/184) and post-operative survival $93 \%, 95 \% \mathrm{Cl} 88-97 \%(138 / 148)$. Female sex, antenatal diagnosis, use of vasodilators or inotropes, being small-for-gestational-age, patch repair and use of surfactant were all associated with infant death. Infants undergoing patch repair had a high incidence of post-operative chylothorax (11/54 vs 2/96 in infants undergoing primary closure) and a long length of hospital stay (41 days, IQR 24-68 vs 16 days, IQR 10-25 in primary closure group). Infants managed with synthetic patch material had a high incidence of chylothorax (11/34 vs 0/19 with biological patch).

Conclusion The majority of infant deaths in babies born with $\mathrm{CDH}$ occur before surgical correction. Female sex, being born small-for-gestational-age, surfactant use, patch repair and receipt of cardiovascular support were associated with a higher risk of death. The optimum surgical approach, timing of operation and choice of patch material to achieve lowest morbidity warrants further evaluation. 


\section{Introduction}

Congenital diaphragmatic hernia $(\mathrm{CDH})$ is an abnormality requiring surgical correction with a relatively high mortality due to lung hypoplasia, aberrant pulmonary vascular biology and associated major anomalies. Short-term survival outcomes from institutions around the world have been extensively reported, with the majority focussing on mortality before initial discharge from hospital $\left.\right|^{1,2,3,4}$. Significant morbidity also accompanies $\mathrm{CDH}$ with medium-term complications including; hernia recurrence, chylothorax, gastro-oesophageal reflux disease (GORD) and prolonged hospital stay ${ }^{5,6}$.

This study reports infant mortality and morbidity in the first year following operation in a national population cohort of children born alive with $\mathrm{CDH}$. Variables related to infant mortality are assessed. Factors associated with death before surgery in this cohort have been reported previously and were found to include: female sex, prenatal diagnosis and the need for inotropes or pulmonary vasodilators ${ }^{7}$. The aim of this analysis was to investigate factors related to all deaths within the cohort including those before surgery and those in the first post-operative year.

In addition to mortality; hernia recurrence, incidence of chylothorax, GORD and length of stay in hospital in the first post-operative year were assessed and their incidence after the use of different surgical techniques are compared. These include comparisons between primary vs patch diaphragm closure, open vs minimally invasive surgery (MIS) and the use of biological vs synthetic patch material.

\section{Methods}

Research ethics committee approval for this study was received from the London Research Ethics Committee: Ref 09/H0718/10. 


\section{Case identification}

Cases were identified and data collected using the British Association of Paediatric Surgeons Congenital Anomaly Surveillance System (BAPS-CASS) described previously ${ }^{8}$. Initial standardised data collection forms were sent to reporting clinicians from all 28 specialist paediatric surgical centres in the UK and Ireland for each of the live-born infants within the population cohort. Data were double entered into a customised database and missing data were sought from reporting centres and clinicians. Further post-operative outcome data were obtained by sending an additional standardised data collection form one year after surgery to all surgical centres for information pertaining to all surviving infants.

\section{Outcome measures}

Data were collected and analysed on death, length of post-operative stay (LOS), chylothorax, GORD and hernia recurrence within one post-operative year. LOS was defined as date of primary operation i.e. $\mathrm{CDH}$ repair, to date of home discharge.

Non-survivors were excluded from the analysis of LOS. Death was defined as either death before surgical correction or death in the first post-operative year. GORD was defined as the use of medication for gastro-oesophageal reflux. Incidence of post-operative pneumothorax(s), adhesive bowel obstruction and neurological sequelae were also documented. Neurological sequelae were defined as any known central nervous system dysfunction including; seizure activity, developmental delay or abnormalities detected on cerebral imaging. 


\section{Statistical analyses}

Stata v13 was used for all statistical analyses. Median and IQR values are presented for continuous data and differences analysed using Mann-Whitney $U$ tests. Due to less-than-complete follow-up for some infants, both minimum and maximum estimated incidences were calculated for some outcomes. These were defined as follows: in both calculations, the numerator was the reported incidence of the outcome at 28 days and, where data were returned, at one-year. For the 'minimum' estimate, the denominator was the total number of children in the cohort. For the 'maximum' estimate, the denominator was the number of children who either; returned follow-up forms, died or reported the outcome in question on the early data collection form. In the case of post-operative outcomes (Tables 1 and S1) denominators were restricted to those children who had undergone surgery.

Risk factors assessed for their relationship with the post-operative outcomes described above included side of hernia, use of a patch, patch material and surgical approach (open or minimally invasive, (MIS).

Univariable and multivariable logistic regression analyses were used to assess factors associated with the risk of infant death. Possible risk-factors were determined a priori from review of the literature and included; baseline demographic variables, antenatal diagnosis and presence of liver in the chest on antenatal ultrasound, markers of physiological instability e.g. use of pulmonary vasodilators or inotropic support and organisational factors such as postnatal transfer and centre case-volume. Factors with a significant odds ratio $(O R)(p<0.10)$ when fitted singly were included in a multivariable model in a forward step-wise method in order of their statistical significance. Those that improved the fit of the model on likelihood ratio testing were retained. Factors with a $p$ value of $<0.05$ within the final model were considered statistically significant/ associated with infant death. 
Small for gestational age (SGA) was investigated as a risk factor for mortality: this was defined as being less than the $10^{\text {th }}$ percentile for birthweight for gestational age using British normative data from the LMS growth study ${ }^{9}$. Birth-weight is collinear with gestational age and related to SGA. This would therefore not be carried forward to the multivariable model alongside either of these factors. Factors that would only be relevant to certain groups of infants e.g. those who had an antenatal diagnosis or those who underwent surgery were also not carried forward into the multivariable model as to do so would have restricted the analysis to these small subsets of infants. Such factors included post-natal transfer and surgical repair type.

\section{Results}

From a live-born cohort of 219 babies with $\mathrm{CDH}, 182$ underwent surgical repair (83\%). Complete follow up was obtained on 184 infants ( $85 \%$ of the original cohort of 219). Overall known survival to one year among the cohort was $138 / 184,(75 \%, 95 \% \mathrm{Cl} 68-81)$.

\section{Post-operative outcomes}

A total of ten infants who underwent surgery died within the following year $(7 \%, 95 \% \mathrm{Cl} 3-12)$ of the 148 infants who underwent surgery in whom complete follow up was available. The timing of postoperative death is shown in Figure 1. The causes of post-operative death were as follows; six had intractable pulmonary hypertension, two were unable to be weaned from ventilation (one of these had severe cerebral atrophy), one had sepsis and the cause of one death was unknown.

Overall length of post-operative stay was 20 days (IQR 11-35 days) for those who survived. Table 1 shows the comparative analysis of the maximum incidence of key post-operative outcomes according to potential risk-factors. The analysis of the minimum incidence results (shown in Table S1) are not markedly different and so all further results and discussion are based on the maximum estimates. 
The hernia recurrence rate was $12 / 150$ (8\%, 4.2-13.6\%). Post-operative chylothorax was observed in only $13 / 150(9 \%, 4.7-14.4)$ infants.

Nine of $52 \mathrm{CDH}$ newborns who had patch repair died post operatively (17\%). The median length of hospital stay in infants having a patch reconstruction was 41 days (IQR 24-68); the median length of stay for babies undergoing primary CDH defect closure was 16 days (IQR 10-25).

Post-operative chylothorax occurred in $20 \%$ of children who underwent patch closure and $2 \%$ of those closed primarily. All chylothoraces following patch closure developed after the use of synthetic patch material e.g Gore-tex ${ }^{\circ}$ Polypropylene or Polyester, (11/34 (32\%)) and none occurred in the 19 infants closed with biological patch material. These were bovine or porcine collagen grafts e.g. Permacol ${ }^{\circ}$, Tutopatch $^{\circledR}$ or Surgisis ${ }^{\bullet}$

The number of infants receiving medical therapy(s) for GOR was $40 / 150(27 \%)$. Over a third of infants closed with a patch were treated with medication for gastro-oesophageal reflux disease $(20 / 53,38 \%)$; a fifth of those who had CDH primary repair had GOR medication (20/97, 21\% infants). Eight of 182 of infants who underwent surgery for $\mathrm{CDH}$ had a fundoplication in the first post-operative year (4\%). Five of these had a Nissen, one was of a Thal type and the other two anti-reflux surgery procedures were of undefined type. The timing of fundoplication was clearly documented in six infants (range 34-247 days) following $\mathrm{CDH}$ primary operation (median 153 days).

Univariable analysis identified ten factors eligible for inclusion in the multivariable model (Table 2). After likelihood ratio testing (significance level 0.05 ), gestational age was the only variable excluded from the final model (Table 3). 


\section{Other morbidity}

Complete data on each of the post-operative morbidities was not obtained for all infants. Data presented here therefore represent those for infants with complete data on each given defined outcome. Twenty infants were reported as having had a pneumothorax after surgery 20/182 (11\%), two of these also had a pneumothorax prior to surgery. Nine of 140 infants (6\%) were known to have experienced adhesive bowel obstruction in the year following $\mathrm{CDH}$ repair. Adhesive bowel obstruction occurred in $3 / 45(7 \%)$ of those closed with a patch and 6/95 (6\%) who had a primary closure. This occurred in $0 / 10$ who had minimally invasive surgery compared with $9 / 130(7 \%)$ in the open group.

Twelve CDH infants were known to have been discharged home on oxygen therapy $12 / 150$ (8\%). Seven of the 42 infants who underwent patch repair went home on oxygen (17\%) compared with 5/108 (5\%) undergoing primary repair. Three children were reported as having early evidence of a pectus chest wall deformity. Fourteen children from the cohort were reported as having associated neurological sequelae. Three of these developed seizure activity and four were described as having developmental delay. 


\section{Discussion}

This UK and Ireland population-based study has shown that the overall survival of live born infants with $\mathrm{CDH}$ was $75 \%$ at one year. It is evident that the major burden of mortality in this population born with $\mathrm{CDH}$ occurs before operation with $78 \%$ of all deaths occurring before surgery and $93 \%$ of stable infants with $\mathrm{CDH}$ who undergo surgery surviving to one year. In addition to the risk factors for early mortality identified in our previous report; antenatal diagnosis, female sex, the need for inotropes and pulmonary vasodilators, this study further identified that being small for gestational age (SGA) is a risk factor for infant mortality in those born with $\mathrm{CDH}$ (aOR 6.6). Forty-one percent of all SGA CDH infants died before one year. This is the first study, to the best of our knowledge, to have identified SGA as a risk factor for mortality in those born with $\mathrm{CDH}$ and we recommend it should be included as a covariate in all future analyses of $\mathrm{CDH}$ mortality in live-born infants. Pulmonary hypoplasia and lung immaturity are likely to be more marked in these infants and affect their major requirement(s) for cardiopulmonary support.

Post-operative survival was also strongly linked to diaphragm defect size and nine of ten children who died after surgery had undergone diaphragm closure with a patch. These findings share common themes with the Canadian CAPSNET CDH population-based studies and the International CDH Study Group Registry both of whom identified a strong relationship between defect size and survival ${ }^{2,4}$.

This study did not demonstrate a relationship between CDH mortality and side of hernia or hospital case volume, factors cited in international publications that have suggested a significant impact on $\mathrm{CDH}$ prognosis ${ }^{10-14}$. The lack of a demonstrable 'volume-outcome relationship' among this CDH cohort herein reported likely relates to the relatively small number of CDH babies cared for in 'low volume' UK and Ireland centres 40/217 (18\%), precluding reliable statistical analysis. No conclusions can, therefore, be drawn from this study about case volume and outcome. 
One year outcome data generated from this nationwide study are valuable for benchmarking, parental counselling and defining survival metrics and compare favourably with a recent large study published from France ${ }^{14}$. Here it is noteworthy that although pre-operative mortality was similar in the UK and Ireland vs France; (17\% UK vs 18\% France), the largest health outcome differences were observed in the mortality rate(s) of babies after CDH operation, $10 / 148$ (7\%) UK, vs $21 / 114$ France $(18 \%)^{14}$. This difference is statistically significantly different $\left(p=0.004\left(\mathrm{Chi}^{2}\right.\right.$ test $\left.)\right)$. These potential background differences are important to note particularly if international randomised controlled trials for interventions for $\mathrm{CDH}$ are planned in the future and /or for the interpretation of those already in progress e.g. the Sildenafil vs iNO for CDH (CoDiNOS trial) $)^{15}$.

When comparing outcomes of different surgical techniques this study noted the fact that median postoperative length of stay appeared different in those primarily repaired with vs. without a patch (40.5 days vs 16 days). Our data suggest that the incidence of post-operative chylothorax may be higher in those repaired with a patch compared with those repaired primarily. Other authors have also found this to be the case ${ }^{16-18}$, whereas others have not ${ }^{19}$. The risk of early hernia recurrence in all CDH infants was $6 \%$ after primary closure vs $11 \%$ in those having a patch. It is noteworthy that few newborns in this series underwent minimally invasive repair ( $n=10$ with complete follow-up). A robust comparison of clinical outcomes in these infants compared with those repaired with conventional open surgery was therefore not possible.

This study is the first such report to suggest that there may be a relationship between the deployment of a synthetic material patch, e.g. Gore-tex ${ }^{\circledR}$ or Polypropylene and post-operative chylothorax. There are, as yet no clear data to suggest the superiority of one patch material over another and a lack of superiority in preventing recurrence was not demonstrated here due to the relatively small number of infants treated in this way ${ }^{20}$. Large scale clinical trials seeking to evaluate patch materials together with high-quality observational studies with meta-analyses may provide future answers. 
Regarding other post-operative outcomes, in the first year, we found that twenty-seven per cent of infants were prescribed medications for gastro-oesophageal reflux disease (GERD) and yet the rate of early fundoplication in the first post-operative year was low (4\%). These metrics are significantly lower than several international published studies ${ }^{5,21}$ reflecting contemporary practice in the UK and Ireland ${ }^{22}$. Adhesive bowel obstruction was an uncommon early event in this series, affecting $6 \%$ infants in the first year after repair. Risk factors for this remain unknown but it is an important to counsel parents about this possible complication prior to discharge $\mathrm{e}^{5,23-4}$.

Early neurological sequelae were likely under-reported here due to the relatively short duration of follow-up (one year). Despite this, some infants were reported by collaborating centres to have developmental impairment(s) and/ or seizure activity. Future well designed studies incorporating large patient numbers in registries/networks may uncover the true incidence of neurological and developmental sequelae including neurosensory impairment, epilepsy and autism ${ }^{25-29}$. Parent groups, supported by medical professionals have long called for a national registry of $\mathrm{CDH}$ infants to prospectively collect data on infant characteristics and outcomes ${ }^{30}$.

This population study reports morbidity and mortality in the first year after birth in live-born CDH infants. Post-operative survival of babies at one year following primary operation was $93 \%$. Infants born with CDH who are SGA were identified as an 'at risk' group for mortality.

The associated well defined relationship(s) between large $\mathrm{CDH}$ defect size as indicated by the requirement for patch repair and adverse clinical outcome is notable. It is clear that technical aspects of operation for $\mathrm{CDH}$ e.g. open vs minimally invasive surgery or choice of prosthetic patch material warrant further evaluation to define patient selection criteria and to inform 'best practice'. 


\section{Acknowledgements}

We acknowledge the support, dedication and hard work of all those who contributed to this study. Sean Marven, Elizabeth Draper, Paul Johnson, Peter Brocklehurst, David Howe and Judith Rankin were involved in the original set-up and design of the study.

\section{Contributorship Statement}

Professors Losty, Knight and Kurinczuk designed and coordinated the study along with the BAPS-

CASS collaboration. Anna-May Long and Kathryn Bunch analysed the data and Anna-May Long wrote the manuscript which was reviewed and edited by all other authors. 


\section{What is already known on this topic?}

- $\quad \mathrm{CDH}$ is a congenital birth defect which carries a high mortality

- Infants with larger defects, requiring patch closure have poorer outcomes than those closed primarily

\section{What this study adds?}

- Infants with CDH have an increased risk of death if they are female, born small for gestational age, given surfactant, have a patch repair or receive cardiovascular support.

- Patch closure may increase the risk of post-operative chylothorax and the possible influence of patch material on chylothorax incidence requires further investigation.

- These outcome data will enable more specific parental counselling and better shared decision-making. 


\section{References}

1. Brindle, M.E., Cook, E.F., Tibboel, D. et al., A clinical prediction rule for the severity of congenital diaphragmatic hernias in newborns. Pediatrics. 2014;134(2):e413-9.

2. Brindle, M.E., M. Brar, and E.D. Skarsgard, Patch repair is an independent predictor of morbidity and mortality in congenital diaphragmatic hernia. Pediatr Surg Int. 2011;27(9):96974.

3. Javid, P.J., Jaksic, T., Skarsgard, E.D., et al., Survival rate in congenital diaphragmatic hernia: the experience of the Canadian Neonatal Network. J Pediatr Surg. 2004;39(5):657-60.

4. Lally, K.P., Lasky, R.E., Lally, P.A., et al., Standardized reporting for congenital diaphragmatic hernia-an international consensus. J Pediatr Surg. 2013;48(12):2408-15.

5. Morini, F., Valfrè, L., Bagolan, P., Long-term morbidity of congenital diaphragmatic hernia: A plea for standardisation. Semin Pediatr Surg. 2017;26(301-310)

6. Losty PD. Congenital Diaphragmatic Hernia: Where and what is the evidence. Semin Pediatr Surg. 2014;23(278-282)

7. Long $\mathrm{AM}$, Bunch $\mathrm{KJ}$, Knight $\mathrm{M}$, et al. Early population-based outcomes of infants born with congenital diaphragmatic hernia. Arch Dis Child Fetal Neonatal Ed. 2018, Jan (E Pub)

8. Owen, A., Marven S. Johnson, P., et al., Gastroschisis: a national cohort study to describe contemporary surgical strategies and outcomes. J Pediatr Surg. 2010;45(9):1808-16.

9. Cole, T.J., The LMS method for constructing normalized growth standards. Eur J Clin Nutr. 1990;44(1):45-60.

10. Skari, H., Bjornland, K., Haugen, G. et al. Congenital diaphragmatic hernia: a meta-analysis of mortality factors. J Pediatr Surg. 2000; 35: 1187-1197

11. Partridge EA, Peranteau WH, Herkert, L., et al,. Right- versus left-sided congenital diaphragmatic hernia: a comparative outcomes analysis. J Pediatr Surg. 2016;51(6):900-2

12. Burgos CM, Frenckner B, Luco M, Harting MT, Lally PA, Lally KP; Right versus left congenital diaphragmatic hernia - What's the difference? J Pediatr Surg. 2017 Oct 12

12. Kane, J.M., Harbert, J., Hohmann, S., Case Volume and Outcomes of Congenital Diaphragmatic Hernia Surgery in Academic Medical Centers. Am J Perinatol. 2015;32(9):84552

13. Harting MT, Hollinger L, Tsao K Aggressive Surgical Management of Congenital Diaphragmatic Hernia: Worth the Effort?: A Multicenter, Prospective, Cohort Study. Ann Surg. 2018 May;267(5):977-982. 
14. Barrière, F., Michel, F., Loundou, A.D., et al., One-year outcome for congenital diaphragmatic hernia: results from the French National Register. J Pediatr. 2017;(17)31328-8

15. Newborns with Congenital Diaphragmatic hernia: inhaled Nitric Oxide or intravenous Sildenafil for pulmonary hypertension. http://www.trialregister.nl/trialreg/admin/rctview.asp?TC=6982: Accessed April 2018

16. Levy SM, Lally PA, Lally KP J Pediatr Surg. 2013 Apr;48(4):724-9. The impact of chylothorax on neonates with repaired congenital diaphragmatic hernia.

17. Casaccia G., Crescenzi F., Palamides S, et al Pediatr Surg Int. 2006 Jul;22(7):585-8. Pleural effusion requiring drainage in congenital diaphragmatic hernia: incidence, aetiology and treatment.

18. Gonzalez R, Bryner BS, Teitelbaum DH, et al. Chylothorax after congenital diaphragmatic hernia repair. J Pediatr Surg. 2009;44(6):1181-5

19. Mills J, Safavi A, Skarsgard ED. Chylothorax after congenital diaphragmatic hernia repair: a population-based study. J Pediatr Surg. 2012 May;47(5):842-6

20. Romao, R.L., Nasr, A., Chiu, P.P., What is the best prosthetic material for patch repair of congenital diaphragmatic hernia? Comparison and meta-analysis of porcine small intestinal submucosa and polytetrafluoroethylene. J Pediatr Surg. 2012;47(8):1496-500.

21. Diamond, I.R., Mah, K., Kim, P.C., et al Predicting the need for fundoplication at the time of congenital diaphragmatic hernia repair. J Pediatr Surg. 2007;42(6):1066-70.

22. Jawaid, W.B., Qasem, E., Jones, M.O., et al Outcomes following prosthetic patch repair in newborns with congenital diaphragmatic hernia. Br J Surg. 2013;100(13):1833-7

23. Jancelewicz, T., Chiang, M., Oliveira, C., Late surgical outcomes among congenital diaphragmatic hernia $(\mathrm{CDH})$ patients: why long-term follow-up with surgeons is recommended. J Pediatr Surg. 2013;48(5):935-41

24. Skari, H., Bjornland K,. Haugen, G., et al., Congenital diaphragmatic hernia: a survey of practice in Scandinavia. Pediatr Surg Int. 2004;20(5):309-13.

25. Danzer E, Hoffman C, D'Agostino JA, et al. Rate and Risk Factors Associated with Autism Spectrum Disorder in Congenital Diaphragmatic Hernia. J Autism Dev Disord. 2018 Jan 30. doi: 10.1007/s10803-018-3472-6. [Epub ahead of print]

26. Antiel RM, Lin N, Licht DJ, Hoffman C et. al. Growth trajectory and neurodevelopmental outcome in infants with congenital diaphragmatic hernia. J Pediatr Surg. 2017 Dec;52(12):1944-1948. 
27. Antiel RM, Lin N, Licht DJ, Hoffman C et.al Neurodevelopmental outcomes at 5years of age in congenital diaphragmatic hernia. J Pediatr Surg. 2017 Mar;52(3):437-443

28. Danzer E, Gerdes M, D'Agostino JA et. al. Younger gestational age is associated with increased risk of adverse neurodevelopmental outcome during infancy in congenital diaphragmatic hernia. J Pediatr Surg. 2016 Jul;51(7):1084-90

29. Danzer E, Gerdes M, D'Agostino JA et. al. Neurodevelopmental outcome at one year of age in congenital diaphragmatic hernia infants not treated with extracorporeal membrane oxygenation. J Pediatr Surg. 2015 Jun;50(6):898-903.

30. CDH UK Parent Group - Personal Communication, 2018 


\begin{tabular}{|c|c|c|c|c|c|c|}
\hline \multirow[b]{3}{*}{ Outcome } & \multicolumn{6}{|c|}{ Characteristic } \\
\hline & \multicolumn{2}{|c|}{ Closure Method } & \multicolumn{2}{|c|}{$\begin{array}{c}\text { Patch Material } \\
\quad(n=53)\end{array}$} & \multicolumn{2}{|c|}{ Approach } \\
\hline & Primary & Patch & Synthetic $^{\dagger}$ & Biologic $^{\ddagger}$ & Open & MIS \\
\hline $\begin{array}{r}\text { Chylothorax } \\
n(\%) \\
\text { Rate/100 }(95 \% \mathrm{Cl})\end{array}$ & $\begin{array}{l}2 / 96(2 \%) \\
2(0.3-7.3)\end{array}$ & $\begin{array}{l}11 / 54(20 \%) \\
20(10.6-33.5)\end{array}$ & $\begin{array}{l}11 / 34(32 \%) \\
32(17.4-50.5)\end{array}$ & $\begin{array}{l}0 / 19(0 \%) \\
0(0-0.2)\end{array}$ & $\begin{array}{l}12 / 140(9 \%) \\
9(4.5-14.5)\end{array}$ & $\begin{array}{l}1 / 10(10 \%) \\
10(2.5-44.5)\end{array}$ \\
\hline $\begin{array}{r}\text { Recurrence } \\
\mathrm{n}(\%) \\
\text { Rate/100 }(95 \% \mathrm{Cl})\end{array}$ & $\begin{array}{l}6 / 97(6 \%) \\
6(2.3-13.0)\end{array}$ & $\begin{array}{l}6 / 53(11 \%) \\
11(4.3-23.0)\end{array}$ & $\begin{array}{l}4 / 33(12 \%) \\
12(3.4-28.2)\end{array}$ & $\begin{array}{l}2 / 19(11 \%) \\
11(1.3-33.1)\end{array}$ & $\begin{array}{l}11 / 140(8 \%) \\
8(4.0-13.6)\end{array}$ & $\begin{array}{l}1 / 10(10 \%) \\
10(2.5-44.5)\end{array}$ \\
\hline $\begin{array}{r}\text { LOS median } \\
\text { (IQR) }\end{array}$ & $\begin{array}{l}110,16 \text { days } \\
(10-25)\end{array}$ & $\begin{array}{l}44,40.5 \text { days } \\
(23.5-67.5)\end{array}$ & $\begin{array}{l}26,43.5 \text { days } \\
(23-73)\end{array}$ & $\begin{array}{l}17,39 \text { days } \\
(24-58)\end{array}$ & $\begin{array}{l}140,21.5 \text { days } \\
(12-41.5)\end{array}$ & $\begin{array}{l}14,12 \text { days } \\
(3-23)\end{array}$ \\
\hline $\begin{array}{l}\text { Death } \\
n(\%) \\
\text { Rate/100 }(95 \% \mathrm{Cl})\end{array}$ & $\begin{array}{l}1 / 96(1 \%) \\
1(0.03-5.7)\end{array}$ & $\begin{array}{l}9 / 52(17 \%) \\
17(8.2-30.3)\end{array}$ & $\begin{array}{l}6 / 32(19 \%) \\
19(7.2-36.4)\end{array}$ & $\begin{array}{l}3 / 19(16 \%) \\
16(3.4-39.6)\end{array}$ & $\begin{array}{l}10 / 138(7 \%) \\
7(3.5-12.9)\end{array}$ & $\begin{array}{l}0 / 10(0 \%) \\
0(0-0.3)\end{array}$ \\
\hline $\begin{array}{r}\text { GOR } \\
\text { Rate/100 }(95 \% \mathrm{Cl})\end{array}$ & $\begin{array}{l}20 / 97(21 \%) \\
21(13.1-30.0)\end{array}$ & $\begin{array}{l}20 / 53(38 \%) \\
38(24.8-52.1)\end{array}$ & $\begin{array}{l}12 / 33(36 \%) \\
36(20.4-54.9)\end{array}$ & $\begin{array}{l}8 / 19(42 \%) \\
42(20.3-66.5)\end{array}$ & $\begin{array}{l}37 / 140(26 \%) \\
26(19.3-34.5)\end{array}$ & $\begin{array}{l}3 / 10(30 \%) \\
30(6.7-65.2)\end{array}$ \\
\hline
\end{tabular}

${ }^{\dagger}$ Synthetic patches were Gore-tex / Polypropylene, Polyester or composite $\quad{ }^{\ddagger}$ Biological patches were bovine or porcine collagen grafts (Permacol ${ }^{\circ}$, Tutopatch ${ }^{\circ}$ or Surgisis ${ }^{\circ}$ )

Table 1. 'Maximum' incidence of given post-operative outcomes according to potential risk-factors 


\begin{tabular}{|c|c|c|c|}
\hline Variable & Survived to $1 \mathrm{yr}$ & Died before 1 yr & OR* $(95 \% \mathrm{Cl})$ \\
\hline Female sex & $58 / 171(34 \%)$ & $27 / 46(59 \%)$ & $2.77(1.41-5.39)^{* *}$ \\
\hline Male sex & $113 / 171(66 \%)$ & $19 / 46(41 \%)$ & \\
\hline White ethnicity & $144 / 170(85 \%)$ & $41 / 45(91 \%)$ & $1.85(0.61-5.61)$ \\
\hline Multiple pregnancy & $10 / 171(6 \%)$ & $1 / 46(2 \%)$ & $0.36(0.04-2.87)$ \\
\hline $\begin{array}{l}\text { Gestational age at } \\
\text { birth } \\
\text { per week GA }\end{array}$ & $\begin{array}{l}\text { Median } 39 \text { weeks } \\
\text { (IQR 37-40) }\end{array}$ & $\begin{array}{l}\text { Median } 38 \text { weeks } \\
\text { (IQR 34-39) }\end{array}$ & $0.83(0.75-0.93) * *$ \\
\hline $\begin{array}{l}\text { Birth-weight } \\
\text { per } 500 \mathrm{~g} \text { increase in } \\
\text { BW }\end{array}$ & $\begin{array}{l}\text { Median 3080g } \\
\text { (IQR 2780-3420) }\end{array}$ & $\begin{array}{l}\text { Median 2735g } \\
\text { (IQR 2035-3100) }\end{array}$ & $0.63(0.49-0.81) * *$ \\
\hline SGA & $16 / 167(10 \%)$ & $11 / 46(24 \%)$ & $2.97(1.27-6.95) * *$ \\
\hline $\begin{array}{l}\text { Pre/ post-natal } \\
\text { diagnosis }\end{array}$ & $92 / 171(54 \%)$ & $42 / 46(91 \%)$ & $9.02(3.10-26.25) * *$ \\
\hline Associated anomalies & $34 / 171(20 \%)$ & $10 / 46(22 \%)$ & $1.12(0.51-2.48)$ \\
\hline Cardiac anomalies & 17/171 (10\%) & $3 / 46(7 \%)$ & $0.63(0.18-2.26)$ \\
\hline Genetic anomalies & $3 / 171(2 \%)$ & $3 / 46(7 \%)$ & $3.91(0.76-20.04)$ \\
\hline $\begin{array}{l}\text { Liver in the chest if } \\
\text { antenatally diagnosed }\end{array}$ & $24 / 92(74 \%)$ & $10 / 42(76 \%)$ & $0.89(0.39-2.07)$ \\
\hline Side of Hernia (L vs R)† & $138 / 169(82 \%)$ & $40 / 46(87 \%)$ & $1.50(0.58-3.84)$ \\
\hline Inotropes used & $88 / 171(51 \%)$ & $45 / 46(98 \%)$ & $42.44(5.72-314.93) * *$ \\
\hline Vasodilators after birth & $41 / 170(24 \%)$ & $36 / 46(78 \%)$ & $11.33(5.17-24.80) * *$ \\
\hline Surfactant used & $32 / 168(19 \%)$ & $21 / 46(46 \%)$ & $3.57(1.78-7.16) * *$ \\
\hline $\begin{array}{l}\text { Treated at a centre } \\
\text { with }<5 \text { cases/yr }\end{array}$ & $32 / 171(19 \%)$ & $8 / 46(17 \%)$ & $0.91(0.39-2.15)$ \\
\hline $\begin{array}{l}\text { Postnatal transfer } \\
\text { (if AN diagnosed) }\end{array}$ & 29/92 (32\%) & $4 / 42(10 \%)$ & $0.23(0.07-0.70) * *$ \\
\hline Patch vs primary & $54 / 171(32 \%)$ & $9 / 10(90 \%)$ & $19.50(2.41-157.82) * *$ \\
\hline
\end{tabular}

*unadjusted odds ratio. SGA- Small for gestational age ** indicates $\mathrm{P}<0.1$ and therefor examined for inclusion in the multivariable model

Table 2. Characteristics of infants who died before one year of age and those who survived 


\begin{tabular}{|l|l|}
\hline Characteristic & Adjusted Odds Ratio* (95\% Cl) \\
\hline Vasodilators after birth & $5.22(2.02-13.49)$ \\
\hline Inotropes used & $12.45(1.50-103.55)$ \\
\hline Female sex & $3.80(1.58-9.14)$ \\
\hline Prenatal diagnosis & $5.44(1.51-19.55)$ \\
\hline Small for gestational age & $6.60(1.71-25.45)$ \\
\hline Surfactant used & $2.63(1.04-6.62)$ \\
\hline
\end{tabular}

*All factors adjusted for all other variables in the model

Table 3. Factors associated with death before one-year 


\begin{tabular}{|c|c|c|c|c|c|c|}
\hline \multirow[b]{3}{*}{ Outcome } & \multicolumn{6}{|c|}{ Characteristic } \\
\hline & \multicolumn{2}{|c|}{ Closure Method } & \multicolumn{2}{|c|}{$\begin{array}{l}\text { Patch Material } \\
\qquad(n=63)\end{array}$} & \multicolumn{2}{|c|}{ Approach } \\
\hline & Primary & Patch & Synthetic $^{\dagger}$ & Biologic $^{\ddagger}$ & Open & MIS \\
\hline $\begin{array}{r}\text { Chylothorax } \\
n(\%) \\
\text { Rate/100 }(95 \% \mathrm{Cl})\end{array}$ & $\begin{array}{l}2 / 118(2 \%) \\
2(0.2-6.0)\end{array}$ & $\begin{array}{l}11 / 64(17 \%) \\
17(8.9-28.7)\end{array}$ & $\begin{array}{l}11 / 41(27 \%) \\
27(14.2-42.9)\end{array}$ & $\begin{array}{l}0 / 22(0 \%) \\
0(0-15.4)\end{array}$ & $\begin{array}{l}12 / 168(7 \%) \\
7(3.7-12.1)\end{array}$ & $\begin{array}{l}1 / 14(7 \%) \\
7(0.2-33.9)\end{array}$ \\
\hline $\begin{array}{r}\text { Recurrence } \\
n(\%) \\
\text { Rate/100 (95\% Cl) }\end{array}$ & $\begin{array}{l}6 / 118(5 \%) \\
5(1.9-10.7)\end{array}$ & $\begin{array}{l}6 / 64(9 \%) \\
9(3.5-19.3)\end{array}$ & $\begin{array}{l}4 / 41(10 \%) \\
10(2.7-23.1)\end{array}$ & $\begin{array}{l}2 / 22(9 \%) \\
9(1.1-29.2)\end{array}$ & $\begin{array}{l}11 / 168(7 \%) \\
7(3.3-11.4)\end{array}$ & $\begin{array}{l}1 / 14(7 \%) \\
7(0.2-33.9)\end{array}$ \\
\hline $\begin{array}{r}\text { LOS, median } \\
\text { (IQR) }\end{array}$ & $\begin{array}{l}110,16 \text { days } \\
(10-25)\end{array}$ & $\begin{array}{l}44,40.5 \text { days } \\
(23.5-67.5)\end{array}$ & $\begin{array}{l}26,43.5 \text { days } \\
(23-73)\end{array}$ & $\begin{array}{l}17,39 \text { days } \\
(24-58)\end{array}$ & $\begin{array}{l}140,21.5 \text { days } \\
(12-41.5)\end{array}$ & $\begin{array}{l}14,12 \text { days } \\
(3-23)\end{array}$ \\
\hline $\begin{array}{l}\text { Death } \\
n(\%) \\
\text { Rate/100 }(95 \% \mathrm{Cl})\end{array}$ & $\begin{array}{l}1 / 118(1 \%) \\
1(0.0-4.6)\end{array}$ & $\begin{array}{l}9 / 63(14 \%) \\
14(6.7-25.4)\end{array}$ & $\begin{array}{l}6 / 40(15 \%) \\
15(5.7-29.8)\end{array}$ & $\begin{array}{l}3 / 22(14 \%) \\
14(2.9-34.9)\end{array}$ & $\begin{array}{l}10 / 167(6 \%) \\
6(2.9-10.7)\end{array}$ & $\begin{array}{l}0 / 14(0 \%) \\
0(0-23.2)\end{array}$ \\
\hline $\begin{array}{r}\text { GOR } \\
n(\%) \\
\text { Rate/100 }(95 \% \mathrm{Cl})\end{array}$ & $\begin{array}{l}20 / 118(17 \%) \\
17(10.7-25.0)\end{array}$ & $\begin{array}{l}20 / 64(31 \%) \\
31(20.2-44.1)\end{array}$ & $\begin{array}{l}12 / 41(29 \%) \\
29(16.1-45.5)\end{array}$ & $\begin{array}{l}8 / 22(36 \%) \\
36(17.2-59.3)\end{array}$ & $\begin{array}{l}37 / 168(22 \%) \\
22(16.0-29.1)\end{array}$ & $\begin{array}{l}3 / 14(21 \%) \\
21(4.7-50.8)\end{array}$ \\
\hline
\end{tabular}

${ }^{\dagger}$ Synthetic patches were Gore-tex / Polypropylene, Polyester or composite $\quad{ }^{\ddagger}$ Biological patches were bovine or porcine collagen grafts (Permacol ${ }^{\circ}$, Tutopatch $^{\circ}$ or Surgisis ${ }^{\circ}$ )

Table S1. 'Minimum' incidence of given post-operative outcomes according to potential risk-factors,taking denominator as number of children who underwent surgery - 


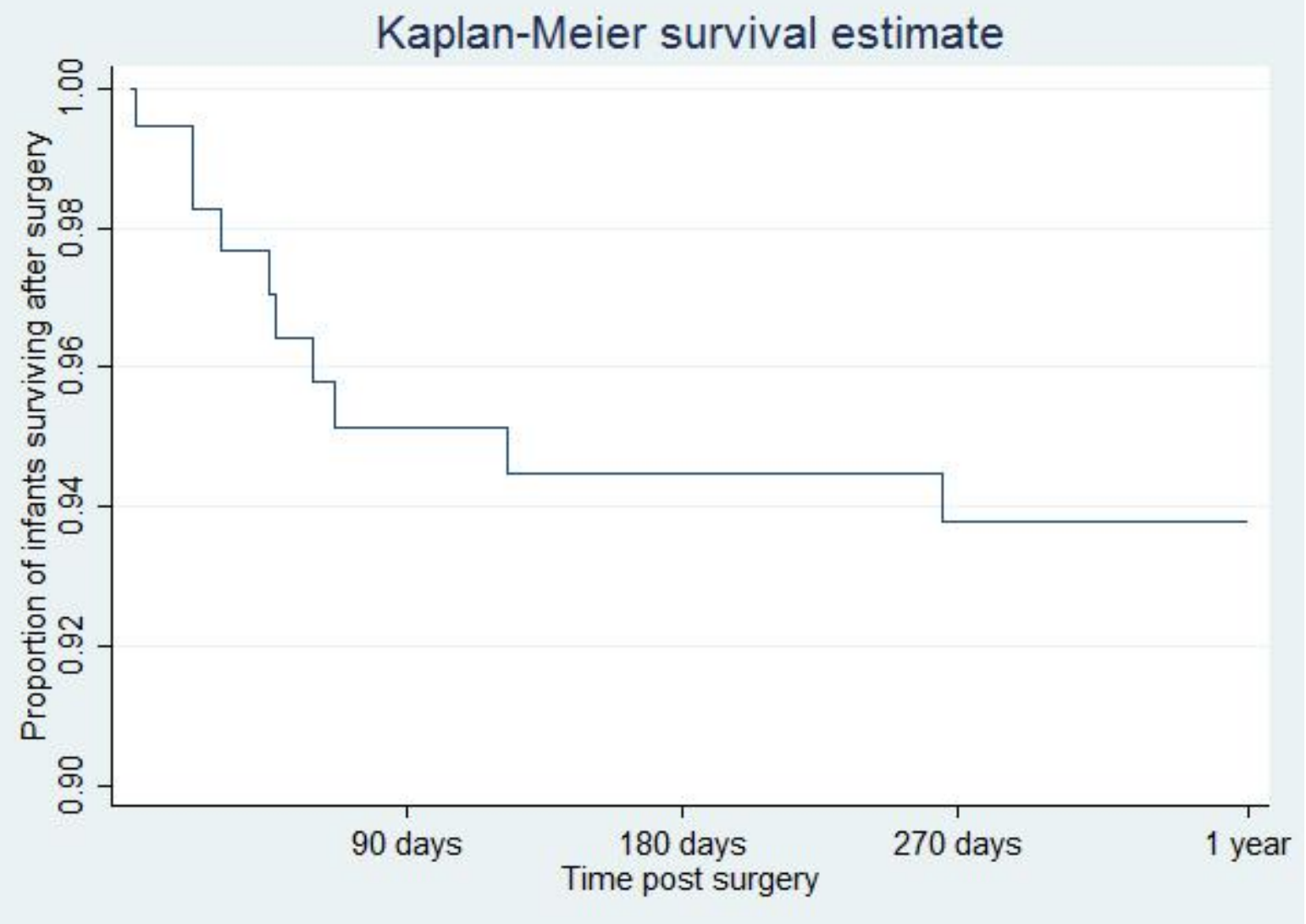

Figure 1. Kaplan Meier graph showing timing of death from surgery in a 12 month period in infants with $\mathrm{CDH}$ 